\title{
UNDERSTANDING DREAMS
}

\author{
Waseem Hassan
}

Preston Institute of Management Sciences and Technology

Corresponding Author: abadallah.wh@gmail.com

"Royal road to the unconscious" as considered by Dr. Sigmund Freud during his dream analysis in 1900 gives a good start to the philosophers when it comes to satisfy their theories in psychophysiological manner. During the early stages of human evolution, there have always been physical and materialistic needs that were to be fulfilled as a necessity of survival. Dreams on the contrary, laid rest in the hands of myth and mysticism and hence been defined in illogical manner which were taken for granted by most of the scholars of the times. Time passed, and the exploration of human psychology became extensively useful for medication and cure of gradually increasing diseases. The point of interest and consideration of scholars were merely diverted to the origination of dreams and the phenomenon of sleeping. It became feasible to study the psyche of behavior when the classification of conscious, sub-conscious, preconscious and unconsciousness were first made.

Dreams have been described by various scientists/psychological scholars as they perceived it to be. As I know and can judge, dream is an illusion or projection of visuals we see every day but with different scenarios we have never been through. It is a process in which the physiological aspects of the body and its psychological responses by the brain are stored in a part of the brain called sub-conscious. It is a part of the mind where the memories are saved and are highly approachable in dreams as all the other functions of the body are hibernated during sleep. Dreams work on $1+1=2$ principal. It states that a specific event, let's say war, was seen in a movie by a person which was stored in his/her subconscious. Later on after 3 days, he/she happens to go in a funeral and weeps a lot. Now the emotions his/her mind perceives from both the movie and funeral was then combined when he's asleep and the brain projects a scenario where that person stuck in an abandoned church where people are crying over their dead ones and the country is on war. A survey was done where 30 people were asked about being injured in dream and suffers pain in same part/organ of the body as they wake up from unbearable pain. Out of all, 4 were able to state that something hit/bit them on the exact area while they were asleep while others were unable to find a reason. Cause and effect is it called where both physiology and psychology is merged in a dream in a single moment of time. The observation was then conducted on a group of 10 people which were pinched while they're asleep. Every subject was pinched with increasing force to see at what point they wake up of pain. Each and every subject explained a different type of scenario from a knife cut to a gunshot in the same part of the body which resulted that each subject undergo pain with their own psychological aspects of bearing specific amount of pain by predefined object which they've either been through in their life or have ever imagined to go through. Now the fact about time; the pain which was injected for 3-5 seconds was felt for minutes in dream. This notifies that the time duration in dream and in this physical world is different from each other. One other aspect, which is still unsolved part of this puzzle, is that either the pain was expected before it is injected and brain projects similar scenario where subject is exposed to pain and the subject feels pain in reality and dream altogether. Or that the subject feels pain in real and it is projected in dream bits of seconds later. Out of all the types of dream which fascinates both psychophysiology and philosophy is lucid dreaming. It is such type of dream in which the person is fully aware that he is dreaming and hence controls his/her actions in dream. Lucidity is a state in which a person accesses his consciousness in unconscious state, i.e. in dream. Most of the lucidity is experienced when a person undergo a false awakening. A false awakening is a state in which a person wakes up in a dream and is convinced that he/she has woken up in physical reality. It usually occurs when a person experiences a dream within a dream. As soon as the dreamer realizes that he/she is still dreaming, the consciousness is activated within a dream. Another fact which is attained by lucid dreaming is: As the level of dreaming increases, (dream within a dream within a dream and so on), the dreamer gradually loses controls on his/her basic senses. For example, a person cannot feel intense pain or shock in a dream and hence is awakened. Similarly, the sense of pain is unable to experience in 2nd level of dreaming and as a person go deeper in dream, the basis senses would start to disappear/decrease gradually. Dreams: From the eyes of Scholars and Researchers: Since the beginning of the understandings of dreams to date, dreams have been divided in several types according to the behavior and nature observed by researcher's globally. Dr. Sigmund Frued (1900) said that dreams are useful in establishing the contents of the unconscious. Since the foundation of unconscious is built in early years of life, before the age of five or six, and consists of repressed material from the psycho-sexual stages, dreams analysis constitutes only a few methods for studying early psychological development. Frued separated the dreams in two kinds of contents: the manifest (conscious) content, a content in which a person dreams something and remembers it, and the latent (unconscious) content, which is then discovered by means of free association. Another study was conducted by Beck and Hurvich (1959). They predicted that depressed patients are likely to have more manifest dreams with masochistic content than other non-depressed patients. They collected a number of dreams from both depressed and non-depressed patients who were scored, and their hypothesis was confirmed at an appropriate level of significance. Carl Jung (1960) was convinced that there was sufficient evidence in dreams and other types of material, e.g., myths and religion, which validated the concept of collective consciousness. While Frued used dreams to study the beginning formative years of a person's life, Jung used them to explore the psychological development of the race. Jung also observed, in contradistinction to Freud, that dreams are oriented to the past as well as to future. They mark out for the individual, the proper path to a more complete actualization of personality and help reveal poorly developed parts of the personality.

\section{CONCLUSION:}

Dreaming is a wider and yet partially unknown aspect of human psychology which is still under exploration as the technology prospers. The above mentioned observations and theories play a 
small part in a wider perspective of human evolution throughout time. It is to be understood that as technological and physical boundaries are being enhanced, the psychological aspects of dreaming and brain accessing is equally important. What my motto is, my observations and research about dreaming would become another step to conquer the complete understanding of dream psychology. As lucid dream makes a perception that we control the specific amount of senses in that dream and consider the dream as our reality, and realizes that we have more than these senses when we wake up, would it be possible that this physical reality is also a dream we are living and understanding this fact, would we be able to control more senses than we do now?

\section{REFERENCES:}

- Freud, S. (1953). Distortion in Dreams. The standard edition of the complete psychological works of Sigmund Freud.

- Beck, A. T., \& Hurvich, M. S. (1959). Psychological correlates of depression: 1. Frequency of" masochistic" dream content in a private practice sample. Psychosomatic Medicine, 21(1), 50-55.

- Jung, C. G. (2010). Synchronicity: An Acausal Connecting Principle.(From Vol. 8. of the Collected Works of CG Jung)(New in Paper) (Vol. 20). Princeton University Press. 